\title{
Dissolution Testing of a Metallic Waste Form in Chloride Brine
}

\section{Scientific Basis for Nuclear Waste Management}

\author{
D. E. Janney
}

November 2006

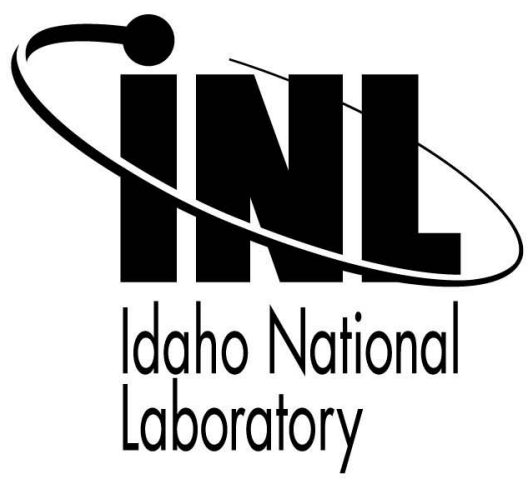

This is a preprint of a paper intended for publication in a journal or proceedings. Since changes may be made before publication, this preprint should not be cited or reproduced without permission of the author. This document was prepared as an account of work sponsored by an agency of the United States Government. Neither the United States Government nor any agency thereof, or any of their employees, makes any warranty, expressed or implied, or assumes any legal liability or responsibility for any third party's use, or the results of such use, of any information, apparatus, product or process disclosed in this report, or represents that its use by such third party would not infringe privately owned rights. The views expressed in this paper are not necessarily those of the United States Government or the sponsoring agency. 


\title{
Dissolution Testing of a Metallic Waste Form in Chloride Brine
}

\author{
D.E. Janney, Idaho National Laboratory, P.O. Box 1625, Idaho Falls, ID 83415-6188
}

\begin{abstract}
Argonne National Laboratory has developed an electrometallurgical process for conditioning spent sodium-bonded metallic reactor fuel from the Experimental Breeder Reactor II (EBR-II). One waste stream from this process consists of a metal waste form (MWF) whose baseline composition is stainless steel alloyed with $15 \mathrm{wt} \% \mathrm{Zr}(\mathrm{SS}-15 \mathrm{Zr})$ and whose microstructure is a eutectic intergrowth of iron solid solutions and Fe-Zr-Cr-Ni intermetallics. This paper reports scanning electron microscope (SEM) observations of corrosion products formed during static immersion tests in which coupons of surrogate MWF containing $10 \mathrm{wt} \% \mathrm{U}$ (SS-15Zr-10U) were immersed in solutions with nominal $\mathrm{pH}$ values of 3 and 4 and $1000 \mathrm{ppm}$ added chloride for 70 days at $50{ }^{\circ} \mathrm{C}$. Although the majority of the surface areas of the coupons appear unchanged, linear areas with localized corrosion products apparently consisting of porous materials overlying corrosion-product-filled channels formed on both coupons, cross-cutting phase boundaries in the original eutectic microstructures. Many of the linear areas intersected the sample edge at notches present before the tests or followed linear flaws visible in pre-test images. Compositions of corrosion products differed significantly from the bulk composition, and the maximum observed concentration of $U$ in corrosion products ( $\sim 25$ at $\%)$ slightly exceeded the highest reported values in actinide-bearing phases in uncorroded surrogate MWF samples with comparable concentrations of $U(\sim 17-19$ at $\%)$.
\end{abstract}

\section{INTRODUCTION}

Argonne National Laboratory has developed an electrometallurgical process for conditioning spent sodium-bonded metallic reactor fuel from the Experimental Breeder Reactor II (EBR-II) prior to disposal at the planned federal high-level radioactive waste repository to be constructed at Yucca Mountain, Nevada. In this process, chopped spent fuel is electrolytically partially dissolved in molten LiCl-KCl eutectic salt. Undissolved material (primarily fuel cladding hulls but also including zirconium, metallic fission products, and a low concentration of actinide elements) will be immobilized in a metal waste form (MWF) whose baseline composition is stainless steel alloyed with $15 \mathrm{wt} \% \mathrm{Zr}$ (SS-15Zr). Scanning electron microscope (SEM) observations of metallic waste forms show eutectic intergrowths consisting of $\sim 50$ volume $\%$ actinide-free iron solid solutions (commonly referred to as "steels") and $~ 50$ volume\% of actinide-bearing Fe-Zr-Cr-Ni intermetallic phases (e.g. References [1] and [2]). Mo is present in low concentrations in both steels and intermetallics [3].

An extensive series of static leach tests was conducted by immersing surrogate MWF ingots with $10 \mathrm{wt} \% \mathrm{U}$ (SS-15Zr-10U) for 70 days at temperatures of 50, 70, and $90{ }^{\circ} \mathrm{C}$ in solutions with $\mathrm{pH}$ values from 3 to 12 and 0 to $10,000 \mathrm{ppm}$ added $\mathrm{Cl}$. The test results support the use of the HLW glass degradation model to represent MWF degradation for purposes of performance assessment for the proposed repository [4]. Studies of apparently uncorroded surfaces of surrogate MWF ingots used in immersion, vapor-hydration, and pulsed-flow tests under a variety of conditions showed formation of surface layers whose compositions were closely related to those of the underlying steel or intermetallic phases in areas that appeared uncorroded and interpreted these layers as passivating [5]. However, these studies contained little information 
about obvious corrosion products and did not address corrosion processes in low-pH chloridebearing solutions.

This paper documents scanning electron-microscope (SEM) observations of corrosion products formed on two coupons of SS-15Zr-10U that were immersed in $\mathrm{pH} 3$ or 4 solutions with $1000 \mathrm{ppm}$ added chloride at $50{ }^{\circ} \mathrm{C}$ for 70 days. Observations such as these are necessary for a mechanistic model of corrosion processes.

\section{EXPERIMENT}

Coupons approximately $1.5 \mathrm{~cm}$ square and $0.2 \mathrm{~cm}$ thick were sawed from an ingot of SS$15 \mathrm{Zr}-10 \mathrm{U}$ and polished to a 1200-grit finish on each side. Each coupon was immersed in a leachate solution prepared by adding $1000 \mathrm{ppm} \mathrm{Cl}$ to a commercially available $\mathrm{pH} 3$ or $\mathrm{pH} 4$ buffer solution. Leachate solutions were changed after 14 days and again after 28 days, and the tests were terminated after 70 days. Samples were removed from the leachate and briefly rinsed with de-ionized water before being placed in new leachate solutions. They were rinsed again and air-dried at the end of the tests. Reference [4] (which refers to these tests as WX series, $\mathrm{pH} 3$ and 4) describes the tests in detail and presents the leach-test results.

Low-magnification SEM images of each side of each coupon were taken before and after the tests. Numerous higher-magnification images and several hundred energy-dispersive X-ray spectroscopy (EDX) spectra were collected from materials that first appeared in the post-test images. The EDX spectra showed that the new materials consisted primarily of $\mathrm{Fe}, \mathrm{Cr}, \mathrm{Ni}, \mathrm{Zr}$, and $\mathrm{U}$, with the possible addition of oxygen and other light elements such as hydrogen. Because these metals are major constituents of the sample and are not present in the initial leachate solutions, the new materials are considered to be corrosion products.

\section{RESULTS}

\section{pH 3 coupon}

Although most of the surface area of the $\mathrm{pH} 3$ coupon appear similar in pre- and post-test low-magnification SEM images, back-scattered electron (BSE) images show thin corrosion products extending inward from three corners on one side of the sample (left half, Figure 1). Several areas with localized linear or gently curving areas of corrosion products intersect the edges of the sample (right half, Figure 1). Examples of steels and intermetallics in the original eutectic microstructure are indicated by "S" and "I" in some figures.

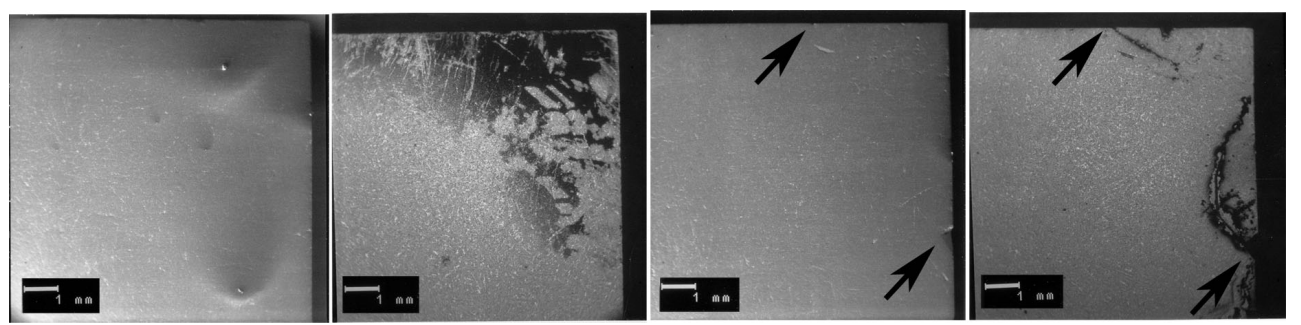

Figure 1. pH 3 coupon. Scale bars: $1 \mathrm{~mm}$. a: Pre-test SE image showing corner of sample. B: Post-test BSE image of area in Fig. 1a. c: Pre-test SE image showing corner of opposite side of sample. D: Post-test BSE image of area in Fig. 1c.

Figure 2 shows the area indicated by the arrow at the top of Figure 1d. Figure 2a was taken before the test, and shows an unidentified linear feature intersecting the edge of the sample at a 
notch. Figure $2 \mathrm{~b}$ shows the same area after the test, with a line of corrosion products following the original linear feature. Figure 2c, a higher magnification view of the area indicated by the arrow in Figure 2b, shows a line of longitudinally grooved corrosion products below the sample surface, surrounded and in some cases covered by porous corrosion products on the sample surface.

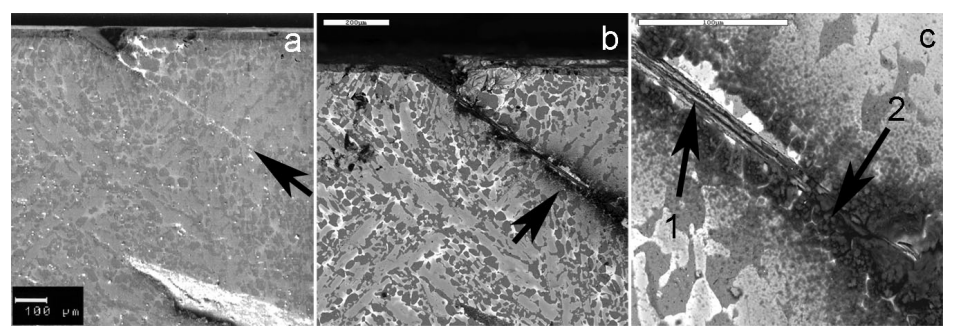

Figure 2. pH 3 coupon. a: Pre-test SE image, scale bar: $100 \mu \mathrm{m}$. Arrow shows linear feature. b: Post-test image of the same area, scale bar: $200 \mu \mathrm{m}$. c: Area shown by arrow in part b, scale bar: $100 \mu \mathrm{m}$. Numbers indicate locations of EDX spectra 1 (material below sample surface) and 2 (material above surface) in Table I.

Figure 3 shows details of two broader bands of corrosion products, both of which occur in channels extending below the sample surface. Edges of the channels are sharp and cut across phase boundaries in the original eutectic microstructure. The material inside each channel has a complex structure with layers approximately parallel to the edges of the channel. Spectra 4, 6, and 7 (Fig. 3b) are from three approximately parallel, light-colored layers, while Spectra 3, 5, and 8 (Fig. 3b) and 11-14 (Fig. 3d) are from darker areas. Spectra 9 and 10 are from surface corrosion products adjacent to a channel.
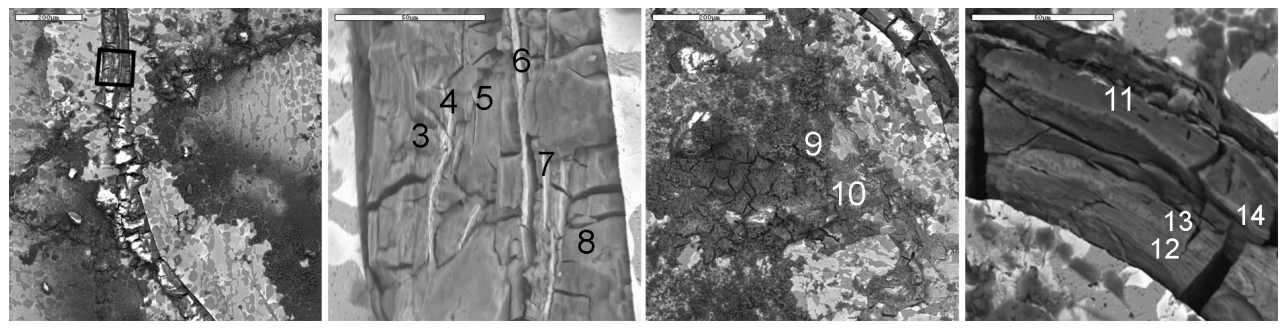

Figure 3. Post-test BSE images, $\mathrm{pH} 3$ coupon. a) Section of curving dark area at right of Figure 1d, scale bar: $200 \mu \mathrm{m}$. b. Area shown by box in part a, scale bar: $50 \mu \mathrm{m}$. c. Section of a curved dark area and adjacent surface deposits, scale bar: $200 \mu \mathrm{m}$. d: Section of curved dark area just above field of view in part c, scale bar: $50 \mathrm{~nm}$. Numbers indicate locations of EDX spectra in Table I.

Figure 4 shows a tilted, approximately triangular area that has been partially lifted above the rest of the sample surface. Spectrum 15 is from corrosion products on the sample surface near the wedge, and 16 is from material below the sample surface adjacent to the uplifted edge of the wedge. Although Spectra 18-21 are currently above the surface of the majority of the sample, they are below the surface of the wedge. Because their morphologies and compositions resemble those of materials in channels, they are interpreted as material that formed below the surface and was raised when the wedge was lifted. 
Recessed areas in the uplifted wedge in Figure 4 suggest that the intermetallic materials and materials along grain boundaries are absent. Steel phases in these areas show extensive pitting. Although the pre-test images do not offer conclusive proof, it seems unlikely that sharp edges and pits such as those visible here could be retained while the sample was ground with 1200-grit paper, and the recessed areas and pits probably formed during the immersion tests.

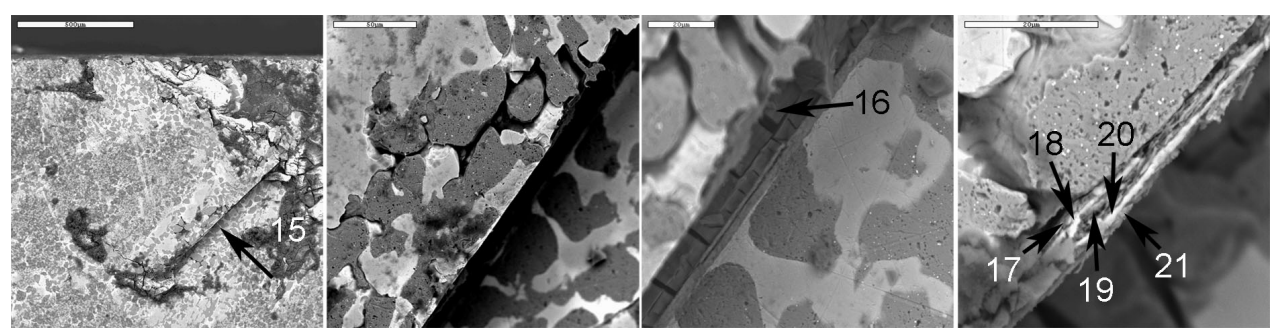

Figure 4. Post-test BSE images, $\mathrm{pH} 3$ coupon. a) Partially uplifted wedge-shaped area, scale bar: $500 \mu \mathrm{m}$. b. Area shown by arrow in part a, scale bar: $50 \mu \mathrm{m}$. c. Layered materials at sample surface (upper right portion of Fig. 4c), scale bar: $20 \mu \mathrm{m}$. d: Layered materials attached to edge of uplifted wedge, scale bar: $20 \mathrm{~nm}$. Numbers indicate locations of EDX spectra in Table I.

Table I. Compositions from EDX spectra in Figures 2-4, normalized to 100 at\% ("L" indicates material in channels that appears light in BSE images, " $D$ " indicates dark-colored material in channels, and " $\mathrm{S}$ " indicates material on the sample surface)

\begin{tabular}{rrrrrrrr} 
Spectrum & Type & $\mathrm{Cr}$ & $\mathrm{Fe}$ & $\mathrm{Ni}$ & $\mathrm{Zr}$ & $\mathrm{Mo}$ & $\mathrm{U}$ \\
\hline 1 & $\mathrm{D}$ & 21.8 & 12.3 & 1.0 & 55.8 & 9.0 & 0.1 \\
2 & $\mathrm{~S}$ & 34.4 & 59.9 & 3.8 & 1.2 & 0.6 & 0.1 \\
3 & $\mathrm{D}$ & 78.4 & 14.5 & 1.4 & 0.5 & 1.5 & 3.7 \\
4 & $\mathrm{~L}$ & 9.7 & 2.0 & 0.7 & 61.0 & 25.8 & 0.9 \\
5 & $\mathrm{D}$ & 80.6 & 14.9 & -1.8 & 5.3 & 0.2 & 0.8 \\
6 & $\mathrm{~L}$ & 2.8 & 2.7 & -1.9 & 77.6 & 18.7 & 0.2 \\
7 & $\mathrm{~L}$ & 6.7 & 5.0 & 0.8 & 63.6 & 22.6 & 1.4 \\
8 & $\mathrm{D}$ & 61.7 & 22.6 & 3.2 & 4.0 & 4.1 & 4.5 \\
9 & $\mathrm{~S}$ & 36.7 & 42.2 & 6.6 & 6.5 & 2.4 & 5.6 \\
10 & $\mathrm{~S}$ & 47.4 & 33.7 & -2.0 & 7.7 & 2.1 & 11.1 \\
11 & $\mathrm{D}$ & 69.8 & 19.8 & -2.2 & 6.1 & 3.2 & 3.4 \\
12 & $\mathrm{D}$ & 63.3 & 19.3 & 2.0 & 2.3 & 5.3 & 7.7 \\
13 & $\mathrm{D}$ & 71.0 & 19.6 & 3.7 & 2.2 & -0.6 & 4.2 \\
14 & $\mathrm{D}$ & 63.3 & 21.0 & -0.6 & 4.4 & 4.1 & 7.8 \\
15 & $\mathrm{~S}$ & 24.0 & 64.9 & 6.0 & 0.8 & 1.7 & 2.7 \\
16 & $\mathrm{D}$ & 42.0 & 35.1 & 4.6 & 5.9 & 4.8 & 7.6 \\
17 & $\mathrm{D}$ & 12.5 & 21.8 & 3.0 & 51.8 & 10.0 & 1.0 \\
18 & $\mathrm{~L}$ & 1.7 & 4.0 & 1.5 & 69.2 & 23.1 & 0.7 \\
19 & $\mathrm{D}$ & 4.9 & 8.6 & 1.9 & 74.8 & 9.6 & 0.3 \\
20 & $\mathrm{~L}$ & 1.1 & 5.0 & 3.4 & 70.3 & 19.7 & 0.6 \\
21 & $\mathrm{D}$ & 26.0 & 55.1 & 5.0 & 9.6 & 2.6 & 1.7
\end{tabular}

Consideration of all of the EDX spectra from the $\mathrm{pH} 3$ coupon (including those in Table I) shows that compositions of corrosion products in channels below the sample surface fall into one 
of two general categories. One category is high in $\mathrm{Cr}$; the second is high in $\mathrm{Zr}$ and Mo. Corrosion products above the sample surface tend to be higher in Fe than those in channels. Proportions of elements in all of the corrosion products do not in general match those in the bulk waste form (which has 16 at $\% \mathrm{Cr}, 1 \% \mathrm{Mn}, 60 \% \mathrm{Fe}, 9 \% \mathrm{Ni}, 11 \% \mathrm{Zr}, 1 \% \mathrm{Mo}$, and 3\% U), in steels, or in intermetallics. The maximum concentration of $U$ in corrosion products $(\sim 25 \mathrm{at} \%)$ is slightly higher than the highest reported concentration of $U$ in a waste form with $11 \% U(\sim 17-19 \%)[1$, 2], and high-U corrosion products are also high in $\mathrm{Cr}$.

\section{pH 4 coupon}

Low-magnification post-test images of the $\mathrm{pH} 4$ coupon are generally indistinguishable from pre-test images. However, several areas with localized areas of new material were observed. As with the $\mathrm{pH} 3$ coupon, some intersected the sample surface at notches present before the test.

Most of the corrosion products visible on the $\mathrm{pH} 4$ coupon appear as highly porous materials above the sample surface. The underlying material can be seen in a few areas where the corrosion products appear to have broken away. Figure 5 shows one such area, which has recessed areas in intermetallic materials and along grain boundaries. Sharp edges on the recessed areas again suggest that they formed during the immersion tests. Corrosion products in sharpedged channels extending below the sample surface were also observed where the porous corrosion products had broken away.
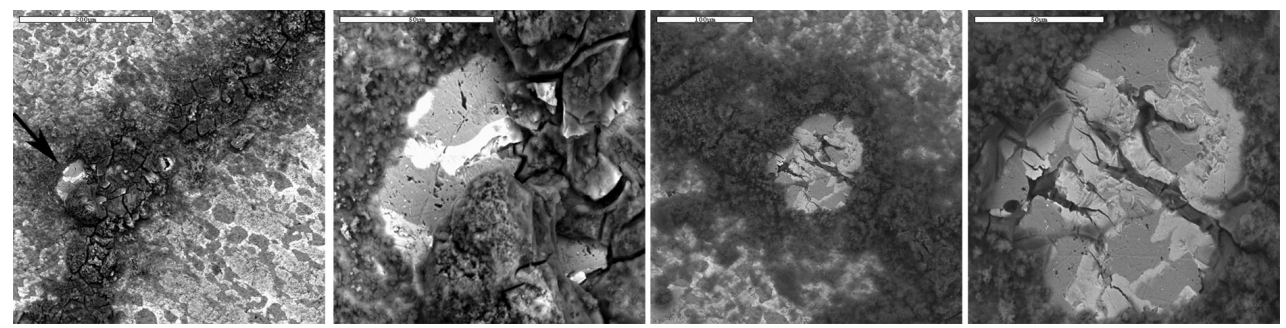

Figure 5. Post-test BSE images, $\mathrm{pH} 4$ coupon. a: Line of corrosion products on sample surface, scale bar: $200 \mu \mathrm{m}$. b: Area indicated by arrow in Fig. 6a, scale bar: $50 \mu \mathrm{m}$. c: Hole in line of corrosion products on sample surface, scale bar: $100 \mu \mathrm{m}$. d: Central part of Fig. $5 \mathrm{c}$, scale bar: $50 \mu \mathrm{m}$.

EDX data from the $\mathrm{pH} 4$ coupon are almost entirely from corrosion products above the sample surface, and consist primarily of $\mathrm{Cr}$ and $\mathrm{Fe}$ in varying proportions. Although the highest concentration of $\mathrm{U}$ is $\sim 17 \%$ (comparable to the maximum reported in uncorroded waste forms with $11 \% \mathrm{U}[1,2])$, correlations between it and other elements are less clear than in the $\mathrm{pH} 3$ coupon. The single spectrum collected from material below the sample surface is from the central part of Fig. $5 \mathrm{~d}$ and shows $30 \% \mathrm{Cr}, 57 \% \mathrm{Fe}, 6 \% \mathrm{Ni}, 3 \% \mathrm{Zr}, 2 \% \mathrm{Mo}$, and $1 \% \mathrm{U}$.

\section{SUMMARY AND CONCLUSIONS}

This paper reports SEM observations of corrosion products formed on SS-15Zr-10U coupons immersed in $\mathrm{pH} 3$ and 4 solutions with $1000 \mathrm{ppm}$ added chloride at $50{ }^{\circ} \mathrm{C}$ for 70 days. Many areas of the sample appear indistinguishable in pre- and post-test low-magnification images. However, both coupons show materials that did not appear in pre-test images of the same parts of the samples. Many of these materials occur in lines that intersect the sample surface at nicks visible in pre-test images or follow linear features visible in the pre-test samples. EDX analyses 
of the new materials indicate that they contain $\mathrm{Fe}, \mathrm{Ni}, \mathrm{Cr}, \mathrm{Zr}$, and $\mathrm{U}$, all of which are present in the samples. Thus, the new materials are interpreted as corrosion products.

Detailed SEM examinations suggest that lines of corrosion products consist of three parts: material in sharp-edged channels below the sample surface, porous material above the surface overlying the channels, and material adjacent to the channels. In many areas, the material on the sample surface above and near the channels appears to have broken away, and its prior existence over all of the channels cannot be proved. Likewise, existence of material below the sample surface underneath lines of porous material cannot be proved. Material adjacent to the channels was not studied in detail, but typically extends a distance of hundreds of nanometers away from each side of the channel, becoming thinner with increasing distance from the channels.

The edges of the channels cut across phase boundaries in the eutectic microstructure of the original waste form. Material within the channels has a layered structure, which appears unrelated to the original phase boundaries. Layers that appear very light-colored in BSE images from the $\mathrm{pH} 4$ sample are high in $\mathrm{Zr}$ and Mo, while darker materials are high in Fe or Cr. Subtle striping in the high-Fe or high-Cr material may represent a finer layered structure. Limited data are available on corrosion products below the surface of the $\mathrm{pH} 4$ coupon, but suggest that they may be higher in Fe.

The corrosion products reported here differ from the surface layers studied in Reference [5] in that they are readily visible in low-magnification SEM images, do not differ in composition depending on whether they are adjacent to steels or intermetallics in the original waste form, and display spatial organization on a scale of hundreds of nanometers to millimeters. Offsets in sample surfaces indicate a volume increase associated with formation of corrosion products. Although the processes responsible for forming the corrosion products studied here remain poorly understood, the corrosion products occur over only a limited portion of the sample surface. The present data do not preclude simultaneous formation of surface layers similar to those reported in Reference [5].

\section{ACKNOWLEDGMENTS}

The work reported here was conducted at the former Argonne National Laboratory-West (now part of Idaho National Laboratory) and at the Idaho National Laboratory. The INL is supported by the U.S. Department of Energy, Office of Nuclear Energy, Science, and Technology, under DOE Idaho Operations Office Contract DE-AC07-05ID14517. The author would particularly like to thank Ms. Tanya Barber, who prepared the samples, collected the pretest data, and conducted the immersion tests, and Dr. Bill Ebert and Ms. Nancy Dietz for helpful discussions of some of the data presented here.

\section{REFERENCES}

1. D.D. Keiser, Jr., D.P. Abraham, W. Sinkler, J.W. Richardson, Jr., and S.M. McDeavitt, J. Nucl. Mater., 279, 234-244 (2000).

2. D.E. Janney, J. Nucl. Mater., 323, 81-92 (2003).

3. D.P. Abraham, D.D. Keiser, Jr., and S.M. McDeavitt, Spectrum '98 Conference Proceedings, 783-789 (1998).

4. W.L. Ebert, M.A. Lewis, T.L. Barber, T. DiSanto, and S.G. Johnson, Argonne National Laboratory Report ANL 03/29 (2003).

5. Dietz, N.L., Argonne National Laboratory Report ANL 05/09 (2005). 